\title{
Jenis Kelamin Perempuan Memiliki Keterampilan Cuci Tangan yang Baik pada Anak Usia Sekolah
}

\author{
Filia Sofiani Ikasari $^{1}$, Agus Setiawan ${ }^{2}$, Sukihananto ${ }^{3}$ \\ ${ }^{1}$ Fakultas Ilmu Keperawatan, Universitas Indonesia \\ ${ }^{2,3}$ Departemen Keperawatan Komunitas, Fakultas Ilmu Keperawatan, Universitas Indonesia \\ Email : filiasofianikasari@gmail.com¹, a-setiawan@ui.ac.id², sukihananto@yahoo.com³
}

\begin{abstract}
Abstrak
Latar Belakang: Anak usia sekolah merupakan anak dengan rentang usia 6 hingga 12 tahun dan pada rentang usia ini anak berisiko terjangkit berbagai penyakit dikarenakan anak banyak menghabiskan waktu di sekolah. Berbagai penyakit tersebut dapat dicegah dengan mempraktikkan cuci tangan yang benar. Salah satu faktor predisposisi dari perilaku mencuci tangan adalah jenis kelamin, namun belum ada hasil penelitian yang sepakat mengenai hubungan jenis kelamin dengan praktik cuci tangan yang benar pada anak usia sekolah.

Tujuan: Penelitian ini bertujuan untuk mengetahui hubungan antara jenis kelamin dengan praktik cuci tangan yang benar pada anak usia sekolah

Metode: Penelitian ini menggunakan desain penelitian cross sectional yang dilakukan di Sekolah Dasar Negeri Jawa 5 Martapura. Responden merupakan siswa sekolah dasar di kelas II, III, IV dan V sebanyak 393 orang yang diperoleh menggunakan teknik simple random sampling. Analisa data menggunakan uji Pearson Product Moment. Intrumen penelitian ini adalah dengan menggunakan kuesioner

Hasil: Hasil penelitian menunjukkan ada hubungan yang signifikan antara jenis kelamin dengan praktik cuci tangan yang benar ( $p$ value $<0,05$ ).

Kesimpulan: Anak usia sekolah dengan jenis kelamin perempuan memiliki skor praktik cuci tangan yang lebih serta terdapat hubungan antara jenis kelamin dengan praktik cuci tangan yang benar pada anak usia sekolah.
\end{abstract}

Kata Kunci: jenis kelamin anak, praktik cuci tangan, anak usia sekolah

\section{Pendahuluan}

Tindakan cuci tangan merupakan salah satu sanitasi dengan membersihkan telapak tangan serta jari-jari dengan sabun atau antimikroba dan dibasuh air, supaya bersih dan sebagai pemutus rantai perkembangan kuman. ${ }^{1}$ Tindakan cuci tangan juga merupakan salah satu upaya dalam mencegah penyakit. Tindakan

\begin{abstract}
Introduction: School-age children were children in the age range of 6 to 12 years and in this age range children have risk of contracting various diseases because children spend a lot of time at school. These diseases can be prevented by practicing proper hand washing. One of the predisposing factors of hand washing behavior was gender, but there are no results of research that agree on the relationship between gender and the correct practice of hand washing in school-age children.

Objective: This study aims was to determine the relationship between gender and the correct practice of hand washing in school-age children

Method: This study used a cross-sectional study design conducted at the Jawa 5 Elementary State School in Martapura. Respondents were elementary school students in grades II, III, IV and V, as many as 393 people were obtained using simple random sampling techniques. Data analysis used Pearson Product Moment test. The instruments of this study used a questionnaire.

Result: The results showed that there was a significant relationship between gender and correct hand washing practices ( $p$ value <0.05).

Conclusion: School-age children with female sex have more handwashing practice scores and there is a relationship between sex with correct handwashing practices in school-age children.
\end{abstract}

Keywords: children's gender, hand washing's practice, school-age children

ini dilakukan karena tangan merupakan agen pembawa kuman, yang menyebabkan patogen berpindah dari satu orang ke lainnya, dengan kontak langsung bahkan tidak langsung (menggunakan permukaan media lain seperti handuk atau gelas). ${ }^{2}$ Mencuci tangan yang benar berdasarkan Riset Kesehatan Dasar Indonesia 
(Riskesdas) pada tahun 2018 adalah dengan cara menggunakan sabun dan air mengalir yang dilakukan sebelum makan, sebelum menyiapkan makanan, setelah memegang uang, memegang binatang, setelah berkebun, setelah buang air besar setelah menceboki bayi atau anak, setelah menggunakan pestisida atau insektisida dan sebelum menyusui bayi.

Mencuci tangan dapat menurunkan kejadian diare sebesar $44 \%$ dan menurunkan kejadian ISPA hingga $50 \%{ }^{3}$ Sehingga mencucui tangan dapat menyebabkan penurunan angka kesakitan dan kematian, serta ketidakhadiran di sekolah di antara anak-anak ${ }^{4}$ Penurunan ketidakhadiran di sekolah dapat mengarah pada peningkatan prestasi anak, yang pada akhirnya dapat memiliki implikasi positif untuk pembangunan bangsa. ${ }^{5}$ Penelitian telah mengungkapkan bahwa siswa yang sering absen atau absen untuk waktu yang lama cenderung mengalami kesulitan menguasai materi yang disajikan di kelas, membuat absensi menjadi masalah pendidikan yang penting. ${ }^{5}$ Oleh karena itu, mencuci tangan memiliki manfaat simultan untuk meningkatkan pendidikan dan kesehatan. ${ }^{1}$

Tangan harus dicuci secara teratur terutama sebelum menyiapkan atau makan makanan, setelah berada di sekitar orang sakit, sebelum dan sesudah merawat luka, setelah membersihkan anak yang menggunakan toilet, setelah menggunakan toilet, setelah menyentuh hewan, pakan ternak, atau kotoran hewan, dan setelah membersihkan atau menyentuh sampah. ${ }^{6}$ Menurut WHO dan Pusat Pengendalian dan Pencegahan Penyakit atau Centers for Disease Control and Prevention (CDC), cara yang tepat untuk membersihkan tangan adalah dengan menggunakan sabun dan air mengalir, kemudian gosok tangan secara bersamaan dan pastikan untuk membersihkan punggung tangan, di antara jari-jari, dan di bawah kuku. ${ }^{6}$ Tujuan mencuci tangan adalah untuk menghilangkan mikroorganisme sementara yang mungkin ditularkan. ${ }^{7}$ Mencuci tangan dengan sabun dan air adalah cara terbaik untuk menghilangkan kuman. ${ }^{8}$ Mencuci tangan merupakan suatu praktik membersihkan tangan dari kuman penyebab penyakit yang merupakan bagian dari perilaku mencuci tangan.

Anak usia sekolah di Indonesia memperoleh capaian terendah perilaku mencuci tangan yaitu sebesar 43\%. ${ }^{3}$ Perilaku mencuci tangan di Kalimantan Selatan masih kurang yakni hanya mencapai $51,7 \% .{ }^{9}$ walaupun angka tersebut telah melampaui capaian rerata perilaku cuci tangan penduduk di Indonesia yakni sebesar $49,8 \% .^{3}$ namun belum mencapai target Menteri Kesehatan Indonesia yaitu 70\% untuk capaian perilaku cuci tangan yang benar. Salah satu kecamatan dengan jumlah penduduk terbanyak di Kalimantan Selatan adalah Kecamatan Martapura yang berada di Kabupaten Banjar yakni sebanyak 113 ribu penduduk. Kasus diare masih banyak ditemukan di Kecamatan Martapura yakni mencapai 103 ribu kasus. ${ }^{9}$ Berdasarkan penelitian yang dilakukan oleh peneliti sebelumnya yaitu Joni dalam Rosyidah mengenai hubungan tingkat pengetahuan, sikap dan perilaku kebersihan siswa sekolah dasar dengan kejadian diare didapatkan ada hubungan antara tingkat pengetahuan, sikap dan praktik siswa tentang kebersihan diri, yang menyebabkan kejadian diare semakin tinggi. ${ }^{10}$

Salah satu faktor predisposisi dari perilaku mencuci tangan adalah jenis kelamin. Hasil observasi yang dilakukan peneliti di beberapa sekolah dasar (SD) negeri Kecamatan Martapura diperoleh bahwa siswa SD hanya menerapkan praktik cuci tangan ketika tangan dirasa kotor, misalnya setelah jajan dan bermain di luar. Hal ini tentu menjadi masalah mengingat waktu penting mencuci tangan menurut Riskesdas tahun 2018 tidak hanya setiap kali tangan kotor melainkan juga dilakukan sebelum makan, setelah buang air besar, setelah menceboki bayi/anak, dan setelah menggunakan pestisida.

Belum banyak penelitian yang membahas mengenai hubungan jenis kelamin anak dengan praktik cuci tangan. Beberapa penelitian sebelumnya belum ada yang sepakat mengenai ada tidaknya hubungan jenis kelamin dengan praktik cuci tangan yang benar pada anak usia sekolah. Dengan mengetahui ada tidaknya hubungan antara keduanya dapat menjadi acuan bagi perawat komunitas untuk memberikan intervensi keperawatan. Perawat komunitas salah satu peran utamanya adalah sebagai edukator. ${ }^{12}$ Dalam memberikan edukasi perawat komunitas menggunakan evidence base practice, jika ternyata terdapat hubungan antara jenis kelamin dengan praktik mencuci tangan maka perawat dapat menggunakannya untuk melakukan modifikasi pendidikan kesehatan agar sesuai dengan kebutuhan anak.

Accepted: 26/02/20

Published:30/30/20 
Berdasarkan fenomena tersebut maka peneliti tertarik untuk meneliti tentang hubungan antara jenis kelamin dengan praktik mencuci tangan yang benar.

\section{Metode}

Penelitian ini menggunakan metode analisis hubungan yaitu bentuk analisis data penelitian untuk mengetahui hubungan di antara variabel. Desain penelitian yang digunakan adalah desain penelitian cross sectional. Penelitian ini dipilih secara acak dari sekian banyak sekolah di Kecamatan Martapura. Populasi pada penelitian ini adalah seluruh siswa sekolah di Kecamatan Martapura. Adapun sampel pada penelitian ini diperoleh menggunakan rumus Slovin sebanyak 393 responden. Instrumen yang digunakan pada penelitian ini adalah kuesioner yang terdiri dari 10 pertanyaan yang dibuat peneliti berdasarkan konsep praktik cuci tangan dari World Health Organization (WHO). Analisa data pada penelitian ini menggunakan uji Pearson Product Moment.

\section{Hasil}

Hasil penelitian analisa univariat mengenai distribusi jenis kelamin responden disajikan pada tabel 1 berikut:

Tabel 1. Distribusi Jenis Kelamin Anak di Sekolah Dasar Negeri Jawa 5 Martapura Tahun 2019

\begin{tabular}{lcc}
\hline Jenis Kelamin & n & Persentase \\
\hline Laki-Laki & 180 & $45,8 \%$ \\
Perempuan & 213 & $54,2 \%$ \\
Total & 393 & $100 \%$ \\
\hline
\end{tabular}

Berdasarkan tabel 1 dapat terlihat bahwa sebagian besar responden merupakan responden dengan jenis kelamin perempuan.

Tabel 2. Analisis Hubungan Jenis Kelamin dengan Praktik Cuci Tangan yang Benar pada Anak di Sekolah Dasar Negeri Jawa 5 Martapura Tahun 2019

\begin{tabular}{|c|c|c|c|c|c|}
\hline Jenis & \multicolumn{3}{|c|}{ Skor Praktik } & \multirow[t]{2}{*}{ Total } & \multirow{2}{*}{$\begin{array}{c}\mathbf{P} \\
\text { value }\end{array}$} \\
\hline Kelamin & $19-26$ & $27-33$ & $34-40$ & & \\
\hline Laki-laki & 20 & 102 & 58 & 180 & 0,01 \\
\hline Perempuan & 17 & 102 & 94 & 213 & \\
\hline
\end{tabular}

Berdasarkan tabel 2 dapat dilihat bahwa responden dengan jenis kelamin perempuan mendominasi untuk skor tertinggi yaitu skor pada rentang 34-40 dibandingkan dengan responden dengan jenis kelamin laki-laki. Selanjutnya hasil analisa hubungan jenis kelamin dengan praktik cuci tangan menggunakan uji Pearson Product Moment menunjukkan adanya hubungan antara jenis kelamin dengan praktik cuci tangan yang benar pada anak usia sekolah dengan $p$ value 0,01 ( $p$ value < 0,05). Hasil penelitian ini menunjukkan bahwa ada hubungan antara jenis kelamin dengan praktik cuci tangan yang benar pada anak usia sekolah. Hasil penelitian ini menunjukkan anak perempuan lebih banyak mempraktikkan cuci tangan dengan benar dibandingkan dengan anak laki-laki.

\section{Pembahasan}

Hasil penelitian ini menunjukkan bahwa ada hubungan antara jenis kelamin dengan praktik cuci tangan yang benar pada anak usia sekolah. Hasil penelitian ini sejalan dengan penelitian yang dilakukan oleh $\mathrm{Al}$ Khatib, Abusara, dan Massoud yang meneliti tentang cuci tangan di antara warga Palestina. ${ }^{8}$ Al-Khatib, Abusara, dan Massoud mendapatkan hasil bahwa sebanyak $89,6 \%$ responden perempuan melaporkan mencuci tangan sebelum makan, dibandingkan dengan responden laki-laki yang hanya sebesar $80,4 \%$ melaporkan mencuci tangan sebelum makan. ${ }^{8}$ Berdasarkan temuan tersebut Al-Khatib, Abusara, dan Massoud menyimpulkan bahwa responden laki-laki cenderung lebih sedikit melakukan cuci tangan dibandingkan dengan responden perempuan. ${ }^{8}$ Hal tersebut didukung oleh penelitian sebelumnya yang dilakukan oleh Harris Interactive yang meneliti tentang kebiasaan mencuci tangan orang Amerika. ${ }^{12}$

Harris Interactive menemukan bahwa sebesar $83 \%$ responden perempuan yang disurvei mengatakan bahwa mereka selalu mencuci tangan sebelum menyentuh makanan dan makan dibandingkan dengan responden laki-laki yang hanya sebesar $71 \%$ melaporkan mencuci tangan sebelum menyentuh makanan dan makan. ${ }^{12}$ Hasil temuan tersebut juga didukung oleh penelitian sebelumnya yang dilakukan oleh Anderson et al yang menyebutkan bahwa praktik mencuci tangan yang lebih baik ditemukan pada responden berjenis kelamin perempuan dibandingkan dengan responden berjenis kelamin laki-laki. ${ }^{13}$ hal tersebut juga sejalan dengan penelitian White et al yang menyatakan hal yang sama bahwa responden dengan jenis kelamin 
perempuan memiliki praktik cuci tangan yang lebih baik dibandingkan dengan responden dengan jenis kelamin laki-laki. ${ }^{14}$ Alasan dibalik temuan tersebut menurut Johnson et al adalah dikarenakan anak perempuan memiliki kecenderungan yang tinggi untuk mempraktikkan perilaku yang dapat diterima secara sosial. ${ }^{15}$

\section{Hasil penelitian ini juga dapat dimaknai} bahwa responden dengan jenis kelamin perempuan lebih memahami pentingnya cuci tangan dibandingkan dengan responden dengan jenis kelamin laki-laki. Hal tersebut dapat terlihat dalam bentuk praktik cuci tangan yang benar lebih banyak dilakukan responden perempuan dibandingkan dengan responden laki-laki. Hal ini disebabkan anak perempuan mengalami lonjakan pertumbuhan pada masa usia sekolah. Anak perempuan lebih tinggi, lebih kuat, dan lebih terampil dalam aktivitas otot kecil sehingga anak perempuan akan lebih memperhatikan kebersihan diri. ${ }^{16}$ Namun hasil penelitian ini tidak sejalan dengan penelitian Kartika, Widagdo dan Sugihantono yang menyebutkan bahwa tidak ada hubungan antara jenis kelamin dengan perilaku cuci tangan. ${ }^{17}$ walaupun mayoritas responden yang mempunyai perilaku cuci tangan yang baik lebih banyak dijumpai pada responden perempuan $(56,8 \%)$ dibandingkan dengan responden laki-laki $(44,4 \%) .{ }^{17}$ Hasil temuan pada penelitian ini juga tidak sejalan dengan dengan penelitian sebelumnya yang dilakukan oleh Cruz et al yang menyebutkan bahwa responden dengan jenis kelamin laki-laki memiliki praktik cuci tangan yang lebih baik dibandingkan dengan responden dengan jenis kelamin perempuan, walaupun begitu, responden dengan jenis kelamin perempuan memiliki sikap yang lebih baik mengenai cuci tangan dibandingkan dengan responden lakilaki. $^{18}$

Responden dengan jenis kelamin lakilaki membutuhkan dorongan lebih untuk terlibat dalam mempelajari praktik cuci tangan yang benar dibandingkan dengan responden dengan jenis kelamin perempuan. ${ }^{18}$ walaupun begitu responden dengan jenis kelamin laki-laki dapat mempraktikkan cuci tangan lebih baik daripada responden dengan jenis kelamin perempuan setelah mendapat dorongan yang lebih, sehingga perbedaan jenis kelamin ini perlu menjadi pertimbangan bagi perawat khususnya perawat komunitas untuk memberikan pendidikan kesehatan dengan metode yang sesuai dengan jenis kelamin anak usia sekolah agar mendapatkan hasil yang efektif.

\section{Kesimpulan}

Kesimpulan dari penelitian ini yaitu anak usia sekolah yang berpartisipasi pada penelitian ini didominasi oleh anak perempuan orang. Temuan dari penelitian ini menunjukkan bahwa ada hubungan antara jenis kelamin dengan praktik cuci tangan yang benar pada anak usia sekolah

\section{Daftar Pustaka}

1. World Health Organization (WHO). A Guide To Implementation Of The WHO Multimodal Hand Hygiene Improvement Strategy. 2009. [cited 22 November 2019]. Available from http://www.who.int/gpsc/5may/Guide to Im plementation.pdf

2. Kementrian Kesehatan Republik Indonesia. Pusat data dan informasi Kementrian Kesehatan Republik Indonesia : perilaku mencuci tangan pakai sabun di Indonesia. 2014. [cited 5 November 2018].

3. Badan Penelitian dan Pengembangan Kesehatan Kementrian RI. Laporan Nasional Riskesdas [internet]. 2019. [cited 21 November 2019]. Available from https://dinkes.kalbarprov.go.id/wpcontent/uploads/2019/03/LaporanRiskesdas-2018-Nasional.pdf

4. Cairncross S, Hunt C, Boisson S, Bostoen K, Curtis V, Fung IC, Schmidt WP. Water sanitation and hygiene for the prevention of diarrhea. IJE. 2010;39:193-205.

5. Malawi Demographic \& Health Survey. Education Data For Decision Making. 2002. [cited 22 November 2019]. Available from http://pdf.usaid.gov/pdf docs/pnacr009.pdf

6. Centers for Disease Control and Prevention. Hand washing: Clean Hands Save Lives. 2012. [cited 22 November 2019]. Available from http://www.cdc.gov/handwashing/

7. Behrman RE, Robert MK, Ann MA. Ilmu kesehatan anak Nelson. Volume 1. Jakarta: EGC; 2000.

8. Al-Khatib IA, Abusara LW, Massoud MA. Hand washing among Palestinians in the west bank and Gaza strip: Attitudes and practices. JEH. 2015;77(6):50-56.

9. Badan Pusat Statistik Kabupaten Banjar. Kabupaten Banjar dalam angka : Banjar regency in figures 2017. BPS Kabupaten Banjar; 2017. 
10. Rosyidah AN. Hubungan Perilaku Cuci Tangan Terhadap Kejadian Diare Pada Siswa Di Sekolah Dasar Negeri Ciputat 02. [Skripsi]. Jakarta: Program Studi Ilmu Keperawatan Universitas Islam Negeri Syarif Hidayatullah; 2014.

11. Allender JA, Rector C, Warner KD. Community and public health nursing: Promoting the public's health. $8^{\text {th }}$ Ed. United States: Lippincott William \& Wilkins; 2014.

12. Harris Interactive. A Survey Of Hand Washing Behavior (prepared for the American Society for Microbiology). 2010. [cited 22 November 2019]. Available from http://www.cleaninginstitute.org/assets/1/As setManager $/ 2010 \% 20$ Hand $\% 20$ Washing $\% 2$ OFindings.pdf

13. Anderson JL, Warren CA, Perez E, Louis RI, Philips S, Wheeler J, Cole M, Misra R. Gender and ethnic differences in hand hygiene practices among college students. Am J Infect Control. 2008;5(36);361-368.
14. White C, Kolble R, Carlson R, Lipson N. The impact of a health campaign on hand hygiene and upper respiratory illness among college students living in residence halls. J Am Coll Health. 2005;53;17581.

15. Johnson HD, Sholcosky D, Gabello K, Ragni $\mathrm{R}$, Ogonosky N. Sex differences in public restroom hand washing behavior associated with visual behavior prompts. Percept Mot Skills. 2003;97;805-10.

16. Click PM, Parker J. Caring for school age children. $5^{\text {th }}$ Ed. Canada: Nelson Education, Ltd; 2009.

17. Kartika M, Widagdo L, Sugihananto A. Faktor-faktor yang berhubungan dengan perilaku cuci tangan pakai sabun pada siswa Sekolah Dasar Negeri Sambiroto 01 Kota Semarang. JKM. 2016;4(5); 339-346.

18. Cruz JP, Cruz CP, Al-Otaibi ASD. Gender difference in hand hygiene among Saudi nursing students. Int J Infect Control. 2015;113. 